\title{
A Rare Case of Calcinosis Cutis: Easily Mistaken as a Foreign Body
}

\author{
Hong II Kim (D), Ho Sung Kim (D), Hyung Suk Yi (D), Hyo Young Kim (D), Yoon Soo Kim (1D \\ Department of Plastic and Reconstructive Surgery, Kosin University College of Medicine, Busan, Korea
}

\begin{abstract}
Calcinosis cutis is a very rare disease characterized by insoluble calcium salt deposits in the skin. There are five types of calcinosis, dystrophic type being the most common among them. Dystrophic calcinosis is generally caused by local tissue damage. We present the dystrophic calcinosis cutis case of a patient with no underlying diseases but a burn injury which occurred 10 years ago. She visited the hospital for an ulcerative wound on the same area. She also had sustained a dog bite injury on the same site 9 months ago, which was treated at an oriental clinic with no improvement. Physical examination by palpation revealed a hard mass under the skin. As the mass was of a large size, the possibility of a foreign body was considered. Surgical resection and biopsy of the mass diagnosed it as dystrophic calcinosis cutis. Although clinical features of this case were unlike previous calcinosis cutis cases, performing a biopsy proved helpful towards its diagnosis.
\end{abstract}

Keywords: Calcinosis; Foreign bodies; Burns; Ulcerative; Dystrophic

\section{Introduction}

Calcinosis cutis is a very rare disease characterized by normal serum calcium levels with high amounts of cutaneous and subcutaneous insoluble calcium salt deposit [1]. There are five types of calcinosis cutis: dystrophic, metastatic, idiopathic or iatrogenic calcification, and calciphylaxis [2]. The dystrophic type is mostly caused by damage of, or abnormalities in, local tissue, whereas the metastatic type is caused by abnormal calcium and phosphorus metabolism. The idiopathic type occurs without any tissue damage, and the iatrogenic type usually occurs after intravenous calcium or paraaminosalicylic acid treatment. Calciphylaxis is related to vasculopathy caused by ischemia or frank tissue infarction [3]. Moreover, calciphylaxis is mainly diagnosed in end stage kidney disease patients, due to the presence of arterial calcification [4].

Dystrophic calcification, the most common type of calcinosis cutis, is linked to various conditions such as connective tissue diseases, inherited disorders, cutaneous neoplasm, infection, radiation, and trauma $[3,4]$. In general, dystrophic calcinosis cutis appears many years after the onset of the underlying conditions described above [5].

The pathophysiology of calcinosis cutis remains unclear, and diagnosis is difficult in the absence of other symptoms such as ulcers or other comorbidities. Diagnoses are typically made based on the patient's clinical features, blood test results, and tissue biopsy results. A standardized treatment is yet to be established; however, there are clinical reports using antibiotics, calcium channel blockers, hyperbaric oxygen (HBO), intralesional corticosteroids, and surgical intervention [4].

Herein, we report a case of a patient who visited our clinic for a chronic wound with a suspected large foreign body under the wound. The patient was diagnosed

\section{Case Report}

Received: November 21, 2020

Revised: March 31, 2021

Accepted: April 7, 2021

\section{Corresponding author:}

Yoon Soo Kim

Department of Plastic and Reconstructive Surgery, Kosin University College of Medicine, 262 Gamcheon-ro, Seo-gu, Busan 49267, Korea

Tel: +82-51-990-6131

Fax: +82-51-990-3005

E-mail: medissu@naver.com

This is an Open Access article distributed under the terms of the Creative Commons Attribution Non-Commercial License (https://creativecommons.org/licenses/by-nc/4.0/) which permits unrestricted non-commercial use, distribution, and reproduction in any medium, provided the original work is properly cited.

(c) 2021 Korean Wound Management Society 
with calcinosis cutis after surgical removal of the suspected foreign body. We obtained written informed consent from the patient. The study was approved by the Institutional Review Board of Kosin University Gospel Hospital (IRB No. KUGH2020-09-007) and performed in accordance with the principles of the Declaration of Helsinki.

\section{Case}

A 69-year-old woman visited our hospital with a main complaint of an ulcerative wound on the right posterior calf. The patient had an unremarkable medical history with no underlying diseases, except for a right posterior calf burn scar from 10 years ago. Prior to the current hospital visit, the patient was treated at an oriental clinic 9 months ago, following a dog bite injury on the existing burn site. However, she visited our hospital because the dog bite site was not healing well for 10 months despite treatment at the oriental clinic.

At the time of presentation, we observed an open chronic

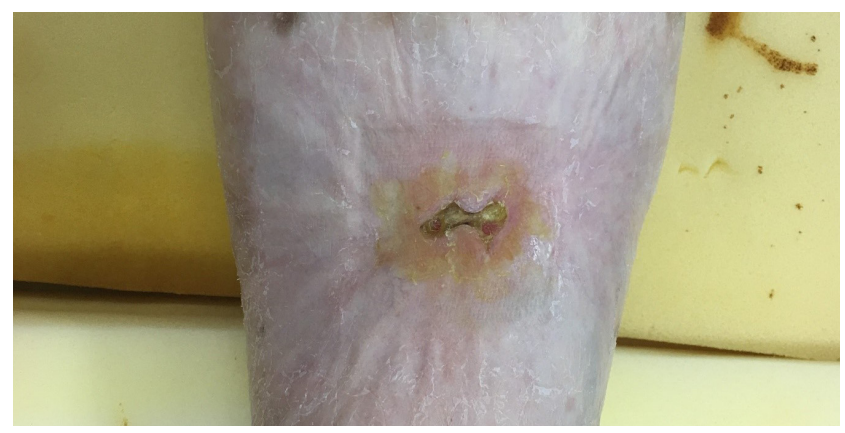

Fig. 1. Preoperative photograph of an ulcerative wound with pus.
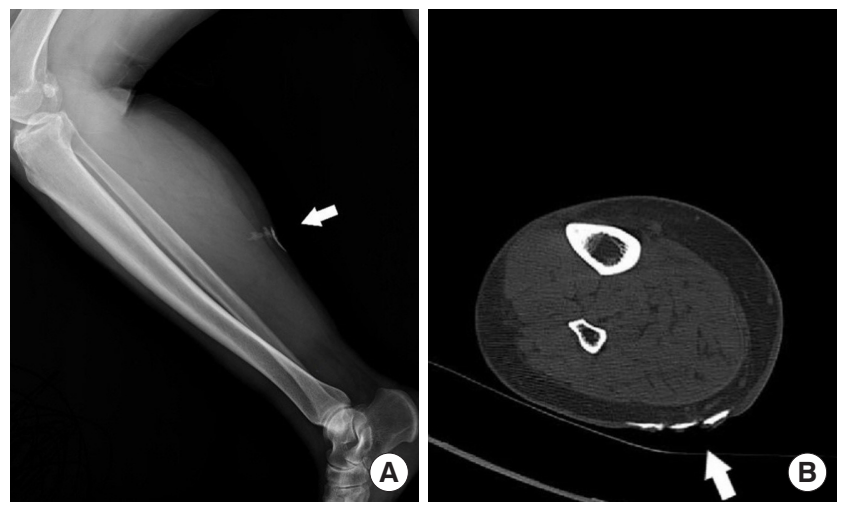

Fig. 2. Preoperative $X$-ray and computed tomography image. (A) Lower leg X-ray and (B) computed tomography scan at the time of first visit. The white arrow indicates a calcified lesion. wound of $2.3 \times 1.5 \mathrm{~cm}$ with purulent discharge, which we considered the dog bite wound. We performed a bacteria culture test of the discharge; however, no bacteria were identified. During physical examination, we palpated a hard mass under the wound which was larger than the wound, and we suspected it to be a large foreign body (Fig. 1). Consequently, an X-ray and lower extremity computed tomography (CT) were performed to evaluate the suspected foreign body. A thin radiopaque plate-like material was detected in the posterior calf by X-ray, and the presence of the foreign body was confirmed by CT (Fig. 2).

We performed a biopsy by resecting $6 \times 4 \mathrm{~cm}$ of skin, containing the ulcer and the mass (Fig. 3). Postoperative splitthickness skin grafting was performed on the excision area.

The graft site healed, and the patient recovered without any complications. Hematoxylin and eosin staining of the biopsy specimen led to a diagnosis of calcinosis cutis (Fig. 4). No calcified lesions were identified in a follow-up X-ray, and the patient reported no recurrences during a 2-year follow-up period (Fig. 5).

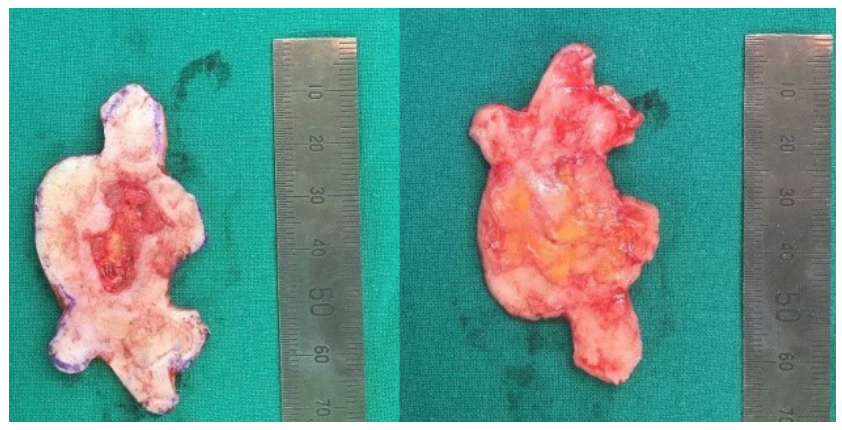

Fig. 3. Intraoperative photograph showing resected calcified tissue. A clinical photograph of hard tissue resected during surgery.

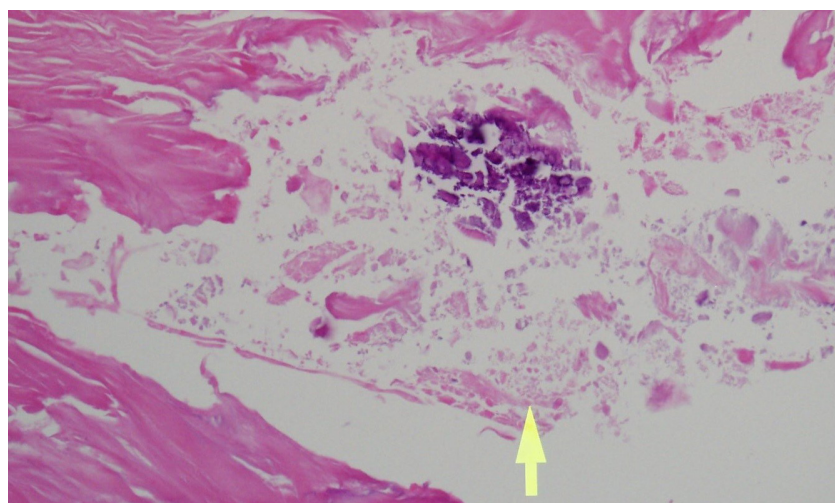

Fig. 4. Histopathological analysis of calcinosis cutis. Surgically resected hard tissue mass. The yellow arrow indicates basophilic-stained calcium deposits $(H \& E, \times 10)$. 

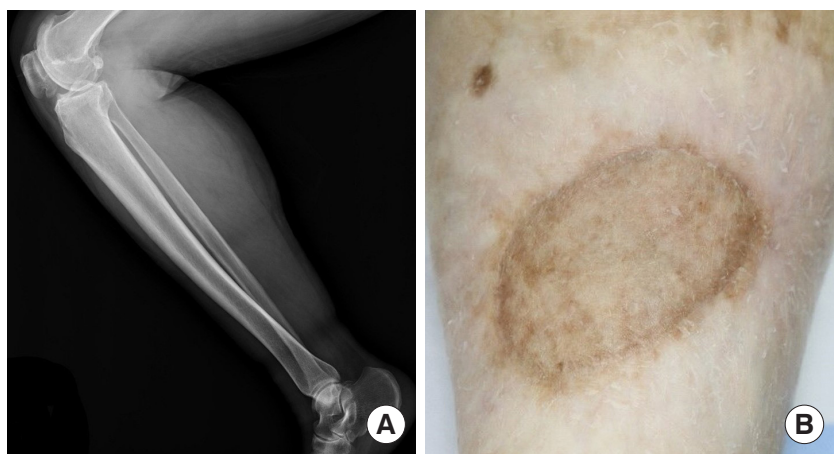

Fig. 5. Postoperative photographs. Two-year postoperative lower leg X-ray (A) and clinical photograph of posterior calf (B). No calcified lesion was identified, and the surgical site favorably recovered.

\section{Discussion}

Calcinosis cutis is a disease caused by abnormal dermal and hypodermal deposition of calcium salts. The clinical features of calcinosis cutis are variable and appear in the form of firm, painless, white, yellowish or flesh-colored papules, plaques, or nodules [6]. Non-healing ulcers are also a non-specific symptom that can occur in all types of calcinosis cutis [3].

The dystrophic type, the most common type of calcinosis cutis, is caused by local tissue injury or abnormalities. It is presumed that an increase in the alkalinity of necrotic tissue leads to calcium salt precipitation [3,7]. In this case, the patient was admitted because of a non-healing chronic ulcer with a suspected large foreign body. However, the biopsy result identified the foreign body as calcinosis cutis, and taking into account the patient's burn history, the diagnosis was dystrophic type calcinosis cutis.

Whatever the mechanism or type of calcinosis cutis, treatment is always challenging. Small calcified deposits or larger localized lesions can be successfully treated with surgical excision. However, extended calcinosis usually requires systemic treatment, such as the use of probenecid, diltiazem, aluminum hydroxide, bisphosphonate, or HBO therapy for several months $[4,8]$. Probenecid, aluminum hydroxide, diltiazem, and bisphosphonate can be used to control serum calcium and phosphate levels and to reduce the size of the calcification [8]. $\mathrm{HBO}$ treatment can increase tissue $\mathrm{pO}_{2}$ levels while reducing tissue edema and ischemia, and inhibit bacterial growth by enhancing angiogenesis. Reducing ischemia by HBO treatment can prevent the development of ischemic eschar, the major cause of calcification formation in calcinosis cutis. $\mathrm{HBO}$ is therefore recommended particularly for inoperable calcinosis cutis patients $[4,9]$. However, the shortcoming of $\mathrm{HBO}$ therapy for calcinosis cutis is that it can only promote healing of the wound without fundamentally curing the disease. Additional treatment options including wound care and correction of hyperphosphatemia are also required.

Among the five types of calcinosis cutis, dystrophic calcinosis cutis is mainly related to autoimmune disease of the connective tissue. However, because it is difficult to treat such diseases, the primary goal of treatment regimens for dystrophic calcinosis cutis is to relieve symptoms and alleviate functional limitations [10].

Patients with trauma-induced calcinosis cutis are not common; however, Larralde et al. [11] reported a case of a patient in whom calcinosis cutis resulted from inguinal fold trauma. In the report, the authors presumed that the tissue injury that caused calcinosis cutis was postoperative inflammation or inflammatory reaction to suture material as a foreign body [11]. In our case, because we initially had limited information from the patient, and considering some reports about complications after foreign body implantation at oriental clinics, we initially presumed the large hard mass to be a foreign body implanted at the local oriental clinic and the un-healing ulcer a result of foreign body infection [12]. However, after the negative bacteria culture, we diagnosed the mass as dystrophic calcinosis cutis, based on pathology examination and trauma history.

While dystrophic calcinosis cutis can occur at the site of a burn scar, the time interval between the burn injury and onset of calcification onset remains very variable. Reiter et al. [3] demonstrated that calcification might occur many years or decades after the injury. Based on literature review, the shortest period of onset was 1.5 years after a pencil tip trauma and the longest period was a report from Heim et al. [13] that occurred 31 years after an injury from boiling water. Therefore, it is difficult to estimate the time from trauma to onset of calcinosis cutis. In our patient, the dog bite injury was too recent to be considered the cause of calcification. Also, the calcification was widely spread under the burn scar, and the area of calcification was wider than that of the dog bite injury. Based on previous case reports and considering the patient's clinical presentations, the cause of calcinosis cutis in the current case was most likely the burn injury.

Meanwhile, there is heterotopic ossification (HO) which develops similar symptoms after burns or trauma [14]. HO is a disease wherein bone formation occurs in soft tissue, and being clinically similar to calcinosis cutis, it is difficult to differentiate by standard imaging investigations. However, $\mathrm{HO}$ can 
be diagnosed histologically using biopsy. While abnormal bone formation is observed in $\mathrm{HO}$, only calcium deposition is observed in calcinosis cutis. Therefore, we diagnosed our patient with calcinosis cutis, based on the presence of calcium deposition in the dermis on histopathological examination.

According to literature, the average size of calcinosis cutis is relatively small [15]. However, in our case, the patient had only one lesion, and it was relatively large $(6 \times 4 \mathrm{~cm})$. This was one of the reasons why the initial presumptive diagnosis was a foreign body rather then calcinosis cutis.

Calcinosis cutis is a very rare disease, and therefore, a subcutaneous hard mass can be easily misdiagnosed as a foreign body or another disorder. Therefore, it is important to perform a biopsy if a non-healing ulcer or hard mass is identified in a patient with a history of trauma, burn, or systemic disease.

\section{Conflict of interest}

This achievement was a research conducted with the support of the National Research Foundation of Korea with the funding of the government (Ministry of Science and Technology Information and Communication) (No. 2020R1G1A100767811). Otherwise, no potential conflict of interest relevant to this article was reported.

\section{ORCID iDs}

Hong Il Kim

Ho Sung Kim

Hyung Suk Yi

Hyo Young Kim

Yoon Soo Kim https://orcid.org/0000-0002-5505-9945

https://orcid.org/0000-0002-6030-3199

https://orcid.org/0000-0002-9584-8201

https://orcid.org/0000-0002-1834-5766

https://orcid.org/0000-0002-8073-5511

\section{References}

1. Bikle DD, Xie Z, Tu CL. Calcium regulation of keratinocyte differentiation. Expert Rev Endocrinol Metab 2012;7:46172.

2. Tak HN, Saldanha P, Pai P. Calcinosis cutis: a study of six cases. Medica Innovatica 2014;3:107-11.

3. Reiter N, El-Shabrawi L, Leinweber B, et al. Calcinosis cutis: part I. diagnostic pathway. J Am Acad Dermatol 2011;65:112.

4. Rogers NM, Coates PT. Calcific uraemic arteriolopathy: an update. Curr Opin Nephrol Hypertens 2008;17:629-34.

5. Lambrescak E, Delanian S. Delayed septic radiation-induced calcinosis cutis long after cured anorectal cancer. Int J Colorectal Dis 2020;35:333-6.

6. Robert L, Kiss N, Medvecz M, et al. Epidemiology and treatment of calcinosis cutis: 13 years of experience. Indian J Dermatol 2020;65:105-11.

7. Lee SY, Kim KS, Kim DY, et al. Dystrophic calcinosis cutis in a patient with squamous cell carcinoma secondary to postburn scar. Ann Plast Surg 2001;46:457-8.

8. Reiter N, El-Shabrawi L, Leinweber B, et al. Calcinosis cutis: part II. treatment options. J Am Acad Dermatol 2011;65:1522.

9. Rogers NM, Chang SH, Teubner DJ, et al. Hyperbaric oxygen as effective adjuvant therapy in the treatmentof distal calcific uraemic arteriolopathy. NDT Plus 2008;1:244-9.

10. Balin SJ, Wetter DA, Andersen LK, et al. Calcinosis cutis occurring in association with autoimmune connective tissue disease: the Mayo Clinic experience with 78 patients, 1996-2009. Arch Dermatol 2012;148:455-62.

11. Larralde M, Giachetti A, Caceres MR, et al. Calcinosis cutis following trauma. Pediatr Dermatol 2005;22:227-9.

12. Baek JH, Chun JH, Kim HS, et al. Two cases of facial foreign body granuloma induced by needle-embedding therapy. Korean J Dermatol 2011;49:72-5.

13. Heim M, Blankstein A, Friedman B, et al. Calcinosis cutis: a rare late complication of burns. Burns Incl Therm Inj 1986; 12:502-4.

14. Ki SH, Sim SH, Ma SH. Subcutaneous heterotopic ossification suspected as skin cancer. J Wound Manag Res 2019;15: 109-2.

15. Muddegowda PH, Lingegowda JB, Ramachandrarao RK, et al. Calcinosis cutis: report of 4 cases. J Lab Physicians 2011;3:125-6. 